\title{
A replicative self-renewal model for long-lived plasma cells: questioning irreversible cell cycle exit
}

\author{
Reuben M. Tooze ${ }^{1,2 *}$ \\ 1 Section of Experimental Haematology, Leeds Institute of Cancer and Pathology, University of Leeds, Leeds, UK \\ ${ }^{2}$ Haematological Malignancy Diagnostic Service, Leeds Teaching Hospitals NHS Trust, Leeds, UK
}

\author{
Edited by: \\ Catherine Pellat-Deceunynck, Centre \\ National de la Recherche Scientifique, \\ France \\ Reviewed by: \\ John D. Colgan, University of lowa, \\ USA \\ Bernard Klein, Institut National de la \\ Santé et de la Recherche Médicale, \\ France \\ *Correspondence: \\ Reuben M. Tooze, Section of \\ Experimental Haematology, \\ Wellcome Trust Brenner Building, \\ Leeds Institute of Cancer and \\ Pathology, St James's University \\ Hospital, Beckett Street, Leeds LS9 \\ 7TF, UK \\ e-mail:r.tooze@leeds.ac.uk
}

Plasma cells are heterogenous in terms of their origins, secretory products, and lifespan. A current paradigm is that cell cycle exit in plasma cell differentiation is irreversible, following a pattern familiar in short-lived effector populations in other hemopoietic lineages. This paradigm no doubt holds true for many plasma cells whose lifespan can be measured in days following the completion of differentiation. Whether this holds true for long-lived bone marrow plasma cells that are potentially maintained for the lifespan of the organism is less apparent. Added to this the mechanisms that establish and maintain cell cycle quiescence in plasma cells are incompletely defined. Gene expression profiling indicates that in the transition of human plasmablasts to long-lived plasma cells a range of cell cycle regulators are induced in a pattern that suggests a quiescence program with potential for cell cycle re-entry. Here a model of relative quiescence with the potential for replicative self-renewal amongst long-lived plasma cells is explored. The implications of such a mechanism would be diverse, and the argument is made here that current evidence is not sufficiently strong that the possibility should be disregarded.

Keywords: plasma cell, cell cycle, self-renewal, quiescence, myeloma, monoclonal gammopathy, gene expression, lifespan

\section{INTRODUCTION}

Entry into cell cycle quiescence accompanies the final phenotypic maturation of plasma cells (1). In short-lived plasma cells the maintenance of quiescence is rendered irrelevant by cell death. In contrast long-lived plasma cells may potentially survive for the lifetime of the organism $(2,3)$, and the mechanisms maintaining quiescence in such populations are of much greater significance. The current paradigm holds that cell cycle exit is permanent and irreversible for all plasma cells $(2,4,5)$. However it may be timely to re-evaluate this paradigm and consider an alternate possibility: that long-lived "memory" plasma cells adopt a quiescent state, controlled by their niche environment, but maintain the potential for replicative self-renewal through cell division. The implications of such a mechanism are diverse, and the evidence against is potentially not sufficiently strong that the possibility should be disregarded. Recent progress in generating and maintaining longlived human plasma cells in vitro may help to address some aspects of this issue.

\section{DISCUSSION}

\section{LIFESPAN OF PLASMA CELLS}

The nature of plasma cell lifespan and the concept of irreversible cell cycle exit accompanying terminal differentiation are intertwined. Early observations of potential plasma cell longevity were largely set aside in favor of the view of continuous generation of short-lived plasma cells $(6,7)$; and in the context of cell cycle exit coupled to functional differentiation, and imminent cell death the concept of irreversible cell cycle exit is natural and follows the prevailing pattern in other short-lived hemopoietic effectors.
The critical transition in our understanding of plasma cell longevity came with the studies of Manz et al. (8) and Slifka et al. (7), whose works combined to provide proof of the existence of long-lived plasma cells, which preferentially resided in the bone marrow and made a central contribution to long-term humoral immunity. Subsequent work from other labs in mouse models has also pointed to extended lifespans, although the half-life predictions vary somewhat with the type of assay and vaccination strategy employed, and in recent data include dynamic changes in long-lived plasma cells in response to systemic inflammation $(5,9,10)$. In earlier continuous tritiated-thymidine incorporation studies in rat, antibody-secreting cells in the bone marrow showed more general labeling reaching near $40 \%$ by 10 days (11), but it has been argued that these experiments may have overlooked long-lived quiescent plasma cells since antigen-specific populations were not assessed (12).

Serological studies in human combined with the persistence of plasma cells after therapeutic B-cell depletion point to significant lifespans for human bone marrow plasma cells (13). While direct evidence of plasma cell longevity in man is limited, in vitro generated human plasma cells can certainly persist as non-dividing cells for months (14). A view of the bone marrow plasma cell compartment, encompassing the decay of antibody titers after therapeutic B-cell depletion, would include a heterogenous mix of plasma cell populations, many with relatively short half-lives in the region of $<100$ days, as well as populations of longer-lived cells persisting well beyond this time-frame. In human bone marrow such heterogeneity is potentially reflected in phenotypic differences in bone marrow plasma cells (G. Arumugakani and A. Rawstron, personal communication). 


\section{DIFFERENTIATION AND THE PERMANENCE OF CELL CYCLE EXIT}

While the shift toward a general acceptance of long-lived bone marrow plasma cell has occurred, the paradigm that all plasma cells have irrevocably exited cell cycle has remained $(2,4,5)$. Terminal differentiation as a concept encompasses the acquisition of high functional specialization and the loss of potential for alternate cell fates. This is frequently linked to irrevocable cell cycle exit. This clearly pertains in the context of short-lived effector cells that die soon after completing differentiation and exiting cell cycle. In contrast in long-lived cells functional specialization is not necessarily linked to irrevocable cell cycle exit (15-19). Schwann cells provide a well-studied example of cells with high functional specialization that enter a quiescent rather than post-mitotic state, and can reenter cell cycle in response to injury or growth factor stimulation (18). However the ability of differentiated cell populations to reenter cell cycle also extends to other systems traditionally viewed as terminally differentiated such as cardiac myocytes $(15,16,19)$. Recently such concepts have also been extended to tissue resident macrophage populations (20-22). Given that such examples exist in other tissues with complex organization, and in immunological populations conventionally viewed as deriving from hemopoietic repopulation, it is reasonable to re-evaluate the paradigm that all differentiated plasma cells have necessarily exited cell cycle in an irrevocable fashion.

While there is little evidence directly in support of long-lived plasma cells undergoing self-renewal by cell division there is also relatively scant data in direct opposition. Several early studies demonstrated that plasma cells but not their proliferating precursors were resistant to hydroxyurea in short-term cultures (23-25). This is consistent with cell cycle exit, but does not distinguish the nature of this quiescence. Phenotypically mature human plasma cells generally lack Ki67 expression by flow cytometry (26), but low levels of proliferating plasma cells are detectable (27), equally flow cytometry only identifies a small fraction of hemopoietic stem cells (HSCs) as detectably in cell cycle (28). The need for long-lived plasma cell renewal may be different in organisms with extended lifespans and longer intervals to sexual maturity, but in the murine studies a slight accumulation of BrdU-labeled antigen-specific plasma cells over time appears to be present in the continuous feeding arm of the original Manz et al. study (8). Additionally an interesting recent study examined pulsed BrdU incorporation into bone marrow plasma cells under a range of immunization scenarios (5). At 60 and 100 days after primary immunization a very low, but above background, level of BrdU incorporation into antigen-specific plasma cells appears to be present. While such data can be interpreted in the context of the prevailing paradigm as newly formed plasma cells arising from B-cell differentiation, it can also be argued that the cell of origin from which a BrdU-labeled plasma cell derives is not known in such studies, particularly after an extended period post immunization. Some or all of the BrdU labeling could derive from incorporation into pre-existing plasma cells that arose following the initial immunization.

\section{CELLULAR RELATIONSHIPS, THE NICHE, AND CELL CYCLE}

Under a range of experimental conditions the process of cell cycle exit during plasma cell differentiation occurs in an orderly fashion (14,29-31), suggesting that the core mechanism is a common feature shared by all plasma cells regardless of cell of origin or activating stimulus. Whether such consistency pertains to the maintenance of cell cycle exit in differentiated plasma cells is less certain. The ability of cellular environment to influence plasma cell biology is a central theme of long-term plasma cell survival and the bone marrow plasma cell niche is critical to the persistence of these cells $(32,33)$. This niche is in part defined by stromal cells that also support multipotent hemopoietic precursors (34). In addition to stromal cells many more fluctuant hemopoietic populations have been implicated as contributing factors to plasma cell survival (3438). This complexity has been summarized in the concept of the multicomponent plasma cell niche (39).

For the principle other long-lived quiescent bone marrow population, the HSC, a remarkably close relationship exists between the niche environment and quiescent state, with a range of niche factors implicated in maintaining quiescence (40-44). Using HSCs as an example, if replicative self-renewal can occur in plasma cells then it is likely that triggers will include changes in niche factors that link quiescence to survival, and physiologic signals that promote transient proliferation. If both quiescence and survival are directly linked to niche occupancy, then the partial displacement of a long-lived plasma cell from its niche, or the depletion of limiting niche factors by competing populations could represent a trigger for replicative self-renewal.

\section{CELL CYCLE IN PLASMA CELL DIFFERENTIATION}

In general clonal expansion precedes plasma cell differentiation representing an intrinsic feature of an effective immune response. In model systems plasma cell differentiation is a process directly linked, at a mechanistic level, to cell division $(23,45-47)$. Indeed whether plasma cell differentiation can occur in the absence of cell division is uncertain. Elegant modeling approaches indicate that the fate adopted by differentiating B-cells is determined in a stochastic fashion linked to cell division (48).

While cell division is thus an essential component of the plasma cell differentiation program, this program does not complete if exit from cell cycle is prevented $(1,30)$. This is not a unique feature of plasma cell differentiation, but a general one of differentiation programs. Indeed much more is known of how cell cycle control intersects with transcriptional programs of cellular differentiation in other lineages (49). General features are that control of G1 progression and regulators of the RB/E2F pathway are central to these processes, but show lineage specific relationships. Furthermore cell cycle regulators can directly impact on transcriptional regulation and the execution of differentiation programs (49).

Direct experimental evidence indicating that cell cycle exit is necessary for plasma cell differentiation comes from analysis of p18INK4C, whose presence in differentiating B-cells is essential for plasma cell differentiation (30). p18INK4C (CDKN2C) is a repressor of the CyclinD-CDK4/6 complex and thus controls the initial phosphorylation of $\mathrm{RB}$ which is required for subsequent hyperphosphorylation by Cyclin-E-CDK complex and G1/S progression (1). CDKN2C is induced in parallel with BLIMP1 (PRDM1), the principle transcription factor defining the committed transition to plasma cell differentiation (50). CDKN2C deficient $\mathrm{B}$-cells induced to undergo plasma cell differentiation express BLIMP1 and initiate the gene expression program of plasma cell 
differentiation, but fail to complete the process of differentiation appropriately, and never achieve the high secretory activity of terminally differentiated plasma cells (30). In a more recent analysis the same laboratory has extended these investigations to examine the transition of highly proliferative "intermediate plasma cells" to mature plasma cells, the former cell state being similar to plasmablasts. CDKN2C was progressively induced from activated $\mathrm{B}$-cell to intermediate and then mature plasma cell state, while CDKN1B (p27KIP1) was selectively induced in mature plasma cell in which both CYCLIN-D2 and -E were also maintained (50). Failure to induce CDKN2C led to cell death amongst "intermediate plasma cells.” These data suggest that cell cycle inhibitors may act sequentially in the differentiation process, and indicate that apoptotic pathways provide a fail-safe controlling plasmablast that do not appropriately exit cell cycle.

A direct link between the differentiation program and cell cycle exit also lies in the ability of BLIMP1 to repress MYC $(51,52)$. BLIMP1 expression accumulates with time during plasma cell differentiation (53), and is well established as a critical regulator of this process necessary to mediate the genetic reprograming from B-cell to plasma cell $(54,55)$. BLIMP1 is implicated in the repression of multiple targets associated with cell proliferation (54), and can bind at the promoters of genes associated with kinetochore function (SPC25 and CENPH) (56), which are also repressed at the plasmablast to plasma cell transition (14), providing an additional mechanism by which it may impact on cell division in plasma cells. Expression of BLIMP1 accumulates during differentiation, precedes the entry into cell cycle quiescence, and is abundantly expressed in mouse and human proliferating plasmablast populations $(14,31,50,53)$. BLIMP1 can recruit several different chromatin modifiers (57-59), which together provide the potential for either labile or stable epigenetic regulation. In a cumulative expression model the gradual increase of BLIMP1 may be linked to sequential and progressively more stable extinction of different gene expression programs. Under such a model the proliferative program would represent a late target repressed once BLIMP1 levels pass a particular threshold at the plasmablast stage. The inability of BLIMP1 to compensate for p18INK4C (50), suggests that the role of BLIMP1 in cell cycle control could lie on the one hand in attenuating the impetus for cell cycle progression and on the other in reinforcing the decision through epigenetic repression of proliferation genes. Nonetheless at present little is known of how the transcriptional program of plasma cell differentiation intersects with the machinery of cell cycle control and exit. While BLIMP1 acts as a regulator of terminal differentiation in both B- and T-cell lineages $(55,60,61)$, this transcription factor can also play roles in cellular populations with stem cell properties (62-65). Thus BLIMP1 expression per se is not necessarily strictly linked to irreversible cell cycle exit.

\section{BLIMP1, BCL6, AND MYELOMA PLASTICITY}

During B-cell differentiation BLIMP1 is involved in counterregulatory relationships with PAX5 (66-68), SPIB $(54,69)$, and BCL6 $(54,70,71)$. These regulatory interactions may be further modified by BACH2 dependent BLIMP1 repression (72-75). Together these interactions play critical roles in limiting and modulating PC differentiation. A notable feature of the "intermediate plasma cells" generated during murine splenic immune responses, was the apparent co-expression of BLIMP1 and BCL6 in a significant fraction of cells (9\%), when analyzed at single cell level (50). However this co-expression was likely to represent a transient state as most cells expressed either factor in a mutually exclusive fashion. Interestingly, in a myeloma cell line model co-expression of BCL6 and MTA3 can drive a phenotypic reversion with B-cell antigen expression (76). Although evidence for BCL6 expression in primary myeloma is limited, some evidence of expression has been observed (77). While BCL6 expression and phenotypic reversion may provide an explanation for observations in advanced myeloma, and myeloma cell lines, it is important to distinguish between such transformed states and those operating in normal plasma cells, and early plasma cell neoplasms. In cell lines and advanced myeloma several co-operating oncogenic events contribute to extensive cell cycle deregulation $(78,79)$. In addition loss of epigenetic control, with a global increase in DNA hypomethylation, is a feature of the monoclonal gammopathy of undetermined significance (MGUS) to myeloma transition (80). Cell proliferation itself imposes a burden on maintaining epigenetic regulation, requiring the re-establishment of appropriate control with each division (81). Thus rapid proliferation is likely to contribute to plasticity of gene expression in advanced myeloma, and may be intrinsically linked to reversion to an "intermediate plasma cell" or plasmablast-like state. Indeed in some instances patients present de novo with disease that blurs the boundaries between "plasmablastic myeloma" and "plasmablastic lymphoma," leading to significant diagnostic and therapeutic questions (82). However, in normal plasma cells, and early neoplasia the balance is strongly in favor of maintaining appropriate epigenetic control and if cell cycle re-entry does occur, then limiting the frequency of this event. Thus, while consideration of phenotypic plasticity and its transcriptional control is relevant in advanced plasma cell malignancies, this must be distinguished from the control processes potentially operating in normal plasma cells, and early plasma cell malignancy under consideration here.

\section{NUCLEAR ORGANIZATION AS A LINK TO STABLE CELL CYCLE EXIT}

A classical feature of mature plasma cells is the organization of the nucleus such that dense chromatin condensation is observed in a ring like pattern at the nuclear periphery (83). This generates the "clock-face" nucleus of the mature plasma cell. The significance of this nuclear architecture is unknown, but compaction of heterochromatin can provide a mechanism contributing to stable gene silencing.

A precedent for this in relation to cell cycle exit can be found in the process of senescence. Cellular senescence is characterized by the expression of a range of cell cycle control proteins, some but not all of which are shared with plasma cells, and the reorganization of the cell nucleus with compaction of silenced chromosome domains into senescence associated heterochromatic foci (SAHF) (84). These domains do not occur in reversibly arrested cells, and are enriched for E2F target genes (84). SAHFs derive from the organization of facultative heterochromatin, associated with tri-methylated H3-K9 and tri-methylated H3-K27, into ordered structures rather than from epigenetic spreading (85-87). Thus if the organization of the plasma cell nuclear heterochromatin 
can be shown to resemble that of SAHFs and contain E2F target genes, it would support a process of irreversible cell cycle exit amongst such cells. If this were the case, failure to establish such highly ordered nuclear structure would be predicted amongst long-lived plasma cell that retain the potential for cell cycle entry, providing a potential mechanistic distinction between such populations.

\section{GENE EXPRESSION CHANGES ASSOCIATED WITH PLASMABLAST TO PLASMA CELL TRANSITION}

One limiting factor in analyzing plasma cell differentiation has been the inability to generate and maintain quiescent mature plasma cells in vitro. The resolution of this problem allowed analysis of the gene expression changes associated both with the differentiation and survival of human plasma cells over time (14). Cell cycle control was amongst the largest and most coherently regulated genetic programs. As expected, genes linked to cell cycle progression, mitosis, and cytokinesis were induced in activated Bcells maintained in plasmablasts and silenced in quiescent plasma cells. Although mRNA expression is not necessarily an accurate readout of protein expression and cell cycle control, nonetheless the gene expression changes linked to the transition from proliferating plasmablast to quiescent and long-lived plasma cells provide an indication of the cell cycle state and the potential processes operating to maintain quiescence (Figure 1).

\section{MYC and CDKN2C}

Consistent with the proposed pattern of regulation from prior studies (52), MYC expression was repressed at the plasmablast to plasma cell transition. CDKN2C ( $p 18 I N K 4 C)$ followed a pattern of expression consistent with its role in murine differentiation being induced initially at the activated B-cell to plasmablast transition and then further induced at the plasmablast to plasma cell transition. Interestingly over the following weeks CDKN2C expression appeared to decay slightly amongst in vitro plasma cells that maintained cell cycle quiescence, and was expressed at only very low level in bone marrow derived plasma cell populations (data not shown) (14). A similar pattern is observed in data from another analysis of plasma cell associated gene expression (http://amazonia.transcriptome.eu/) (31). The data in human plasma cells would suggest therefore that CDKN2C expression is not maintained.

\section{CDKN1A and CDKN1B}

Amongst other negative regulators of the G1/S cell cycle checkpoint CDKN1A ( $p 21 C I P 1 / W A F 1)$ was initially modestly expressed

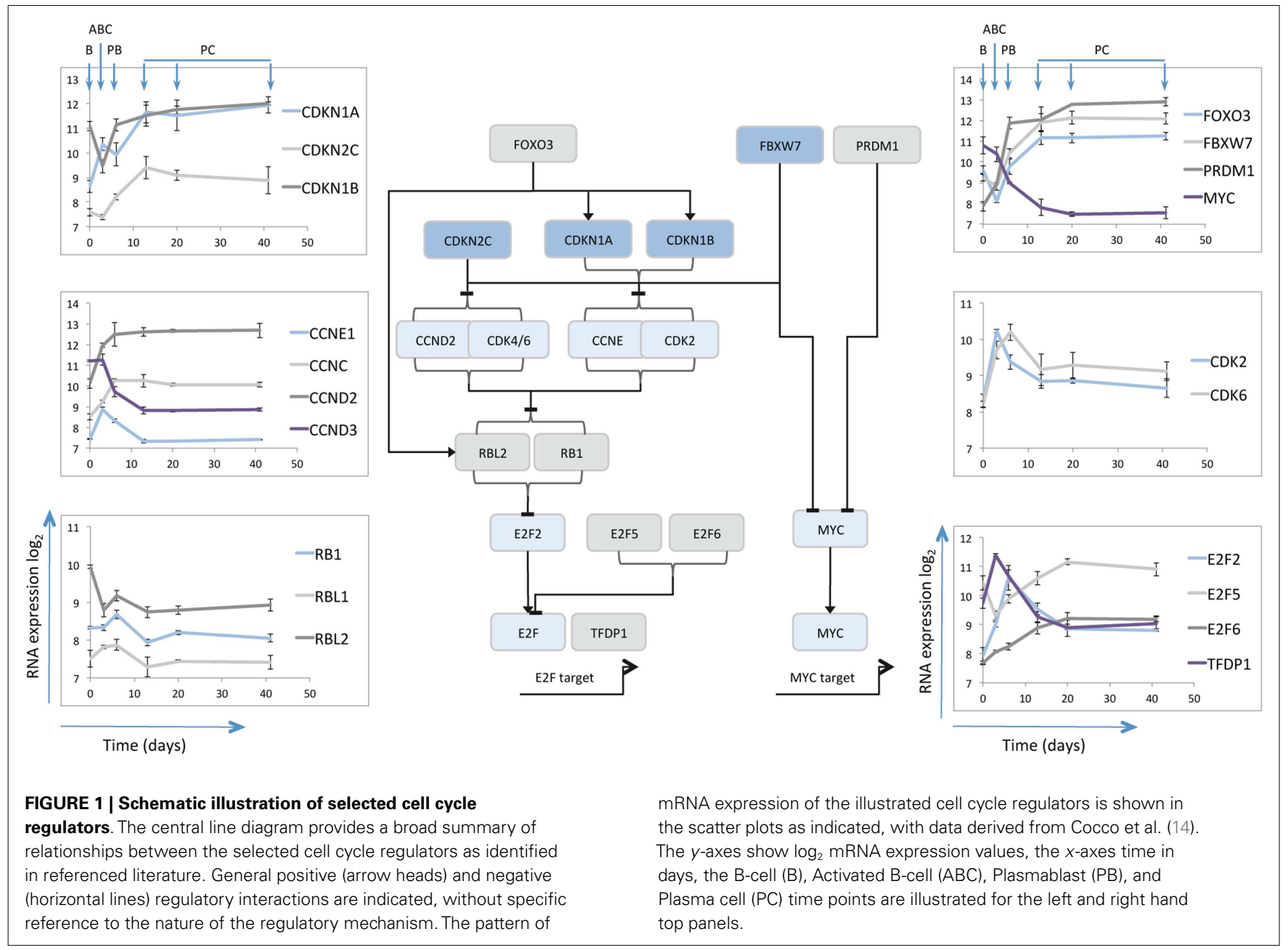


in resting B-cells induced in activated B-cells maintained at slightly lower level in plasmablasts and then sustained at high level in plasma cells. CDKN1B ( $p 27 K I P 1)$ was expressed in B-cells, repressed in activated B-cells and induced and then maintained in plasmablasts and plasma cells. These data would therefore support the contention that CDKN1B (p27KIP1) co-operates with CDKN2C (p18INK4C) in contributing to G1/S checkpoint regulation (50), but suggest that in human plasma cells CDKN1A also contributes. Given the gradual loss of CDKN2C following differentiation the expression patterns support the argument that CDKN1A and CDKN1B are preferentially involved in restraining cell cycle progression once quiescence is established. Additionally the interaction of these proteins with the differentiation program may extend beyond the control of cell cycle. Thus in oligodendrocyte differentiation CDKN1B promotes cell cycle exit, while CDKN1A is linked to expression of the differentiated cell program in cells which have already exited cell cycle (88).

\section{E2F5 and 6}

The expression patterns of $C D K N 2 C$ and $C D K N 1 A / B$ at the plasmablast/plasma cell transition point reflect the central theme of G1/S control in cellular differentiation and senescence programs $(49,89)$, with common convergence on the control of RB phosphorylation and repression of E2F transcription factors. The E2F family includes both activators and repressors of transcription, which dimerize with transcription factor DP1 (TFDP1) to bind at common consensus sequence (90). TFDP1 is dynamically regulated showing maximal expression in activated B-cells, but sustained expression at lower levels in plasma cells. The mRNA for activatory family member E2F2 shows a similar pattern but with maximal expression in plasmablasts, rather than activated B-cells, and is progressively repressed with sustained plasma cell longevity. In contrast the repressive E2F family members E2F5 and E2F6 are distinguished by maximal expression in plasma cells. Coexpression of E2F5 and E2F6 in the absence of E2F7 is observed in quiescent rather than senescent cells (91). While E2F7 can provide a link between RB and cellular senescence programs (91), E2F7 mRNA was not induced upon plasma cell differentiation.

E2F family members, including E2F6, show extensive overlap in binding of DNA elements across the genome (92). However the specific expression of E2F6 mRNA in plasma cells is of interest since E2F6 has been shown to repress E2F and MYC target genes in G0 in complex with TFDP1 and polycomb group proteins (93). Indeed E2F6 can be found in combination with several distinct functional partners implicated in the regulation of chromatin state such as EZH2, BMI1, and L3MBTL2 (94-96). Each of these genes is expressed at some level in plasma cells, but BMI1 is notable for showing a progressive increase over time. Thus the induced expression of E2F6 upon plasmablast to plasma cell differentiation may support the maintenance of the quiescent cell state and has the potential to contribute to epigenetic repression of cell cycle genes $(93,96)$.

\section{Cyclins}

While Cyclin-E (CCNE) mRNA was induced acutely in activated $\mathrm{B}$-cells and then repressed, Cyclin-D3 (CCND3) decreased rapidly during the differentiation. Cyclin-D2 (CCND2) mRNA by contrast increased rapidly and was maintained at stable levels in quiescent plasma cells that no longer expressed genes associated with active cell proliferation. This is similar to the expression pattern reported in murine plasma cells (50). CDK6 showed a spike of expression in activated B-cells and plasmablasts and was maintained at low level in mature plasma cells.

The re-entry from quiescent G0 into the G1 phase of the cell cycle can be regulated by a CCNC/CDK3 complex (97). While $C D K 3$ expression was not detected, CDK2 also acts as a potential alternate CCNC partner (98), and its mRNA was expressed at similar levels in plasma cells as in resting B-cells. CCNC can also act in complex with CDK8 to regulate RNA-polymerase II phosphorylation (99), but CDK8 mRNA was minimally expressed throughout the differentiation series. In human HSCs CCNC acts in control of quiescence, with overexpression of CCNC linked to reduction and loss of CCNC to enhancement of HSC quiescence (100). It is therefore notable that $C C N C$ expression increased on transition from plasmablast to plasma cell state, possibly providing a mechanism along with sustained CCND2 mRNA expression, to poise plasma cells for cell cycle re-entry.

\section{TP53, RB1, and RBL1/2}

TP53, RB1 and their homologs are central to pathways of cell cycle control, and both TP53 and RB dependent pathways co-operate in the robust cell cycle exit of senescence (89). CDKN1A is a core TP53 target and its transcriptional up-regulation could be indicative of a TP53 dependent pathway in plasma cells. At mRNA level TP53 showed modest induction in activated B-cells, at the peak of proliferative response but was subsequently present at very low level.

$R B 1$ was expressed at modest levels up to the plasmablast stage, but decreased at mRNA level on plasma cell maturation. $R B L 1$ (p107) was minimally expressed throughout differentiation, while RBL2 (p130) displayed the most sustained expression levels. Interestingly a functional co-operation between CDKN1B and RBL2 has been identified in hemopoietic cells, and in B-cells combined deficiency of these genes leads to hyper-responsiveness to mitogenic stimuli (101).

\section{FBXW7 and FOXO3}

Beyond genes encoding proteins that are direct controllers of cell cycle progression and exit, other genes notably induced at the plasmablast to plasma cell transition include FBXW7 and FOXO3 both of which play important roles in the control of HSCs (102104). FBXW7 is a component of the SCF-ubiquitin ligase complex and is responsible for targeting several cell cycle promoting factors including MYC and CCNE for degradation (105). Thus expression of FBXW7 can provide a mechanism to actively control pro-proliferative stimuli.

The FOXO family of transcription factors, including FOXO3, is linked to control of cell cycle progression, apoptosis, and stress resistance (106). FOXO3 can drive cell cycle exit through transcriptional regulation of CDKN1B (p27) and RBL2 (p130) (107), both of which as noted above are expressed in plasma cells. Additionally FOXO3 can induce CITED2 (108), a transcriptional co-regulator, which in HSCs is implicated in cellular survival pathways (109), and is also induced at the plasmablast to plasma cell transition. 
FOXO3 is itself a target of the PI3K pathway via AKT or SGK1 $(110,111)$. PI3K signaling is necessary for earlier stages of plasma cell differentiation (112), but has not been examined in detail in differentiated plasma cells. If FOXO3 expression is linked to control of CDKN1B and RBL2 in plasma cells then activation of the $\mathrm{PI} 3 \mathrm{~K} / \mathrm{AKT}$ pathway may provide one means of promoting cycle re-entry.

\section{Combined expression pattern}

The gene expression changes during human plasmablast to plasma cell transition and subsequent maintenance are consistent with the model that cell cycle exit is established through the combined action of CDKN2C (p18), CDKN1A (p21), and CDKN1B (p27) (50), with the latter two showing more consistent expression once cell cycle exit is established. The sustained expression of RBL2 offers a potential direct co-operation with $C D K N 1 B$ (101). In parallel expression of E2F5 and E2F6 provides additional regulators that can maintain G0 quiescence (90). While FOXO3A identifies a potential upstream control pathway for negative cell cycle regulators (106), which is known to be responsive to PI3K/AKT signaling (110), FBXW7 expression provides the potential for degrading mediators of cell cycle progression (105). In parallel the up-regulation of $C C N C$ and sustained expression of a potential CDK partner (CDK2) as well as CCND2 and CDK6 mRNAs, could comprise a latent trigger for G0/G1 re-entry $(97,98)$. At a population mRNA level the induction of plasma cell quiescence is therefore associated with expression of several tiers of cell cycle repressive genes, accompanied by retained expression of cell cycle activators. This suggests the potential for regulated cell cycle re-entry.

\section{MONOCLONAL GAMMOPATHY: AN EXPECTED MANIFESTATION OF SELF-RENEWING PLASMA CELL POPULATIONS?}

Prior to the development of aggressive myeloma, the majority of patients pass through a clinically detected or retrospectively identifiable period of indolent plasma cell neoplasia $(113,114)$. At the earliest stages this is characterized by the presence of a paraprotein and very low percentages of phenotypically aberrant plasma cells in the bone marrow, and is known as MGUS (115). The evolution from indolent to aggressive myeloma is thought to occur with both linear and branching patterns (79, 116-118).

In the context of the prevailing paradigm of plasma cell differentiation, the irreversible nature and the requirement for cell cycle exit in order to complete differentiation should oppose malignant transformation of mature plasma cells. This presents a potential conundrum when considering the pathogenesis of plasma cell malignancies, in particular the more indolent precursor states. There are two principle models of plasma cell malignancy: the first is that neoplastic plasma cells acquire sufficient oncogenic deregulation to escape the normal process of cell cycle exit and thus have the potential to clonally expand and progress over time $(78,79)$; the second is that the phenotypic plasma cell population of the malignancy is supported by a population of clonally related B-cells that act as tumor progenitors to maintain the myeloma plasma cell population (119-123). Given the complexity of human disease, each of these models may pertain in at least some instances. However while B-cell populations related to the malignant plasma cell clone are widely described $(124,125)$, they are not universally detected (126). Clonotypic B-cells in the peripheral blood have been found to possess early but not late oncogenic events of the myeloma clone (127). Furthermore myeloma cells expressing CD138 maintain the tumor upon transplantation into immunodeficient mice (128); and these results have been extended in recent studies showing that the capacity to establish and sustain the tumor in immunodeficient mice resides in malignant plasma cells, some of which lack CD138 expression, but not in clonotypic B-cells (129-131). Overall therefore there is strong evidence that in many instances of myeloma the disease is maintained in the neoplastic plasma cell compartment.

Given that in established myeloma the disease is maintained amongst plasma cells, earlier indolent plasma cell neoplasms including MGUS are also likely to be maintained by the neoplastic plasma cells themselves. However in this context the fraction of cells in cycle is very low, as are the number of transforming oncogenic events, while the accumulation of oncogenic events associated with cell cycle deregulation occurs later in plasma cell transformation $(78,79,115,118)$.

In MGUS and early myeloma, phenotypic differentiation is not prevented and the majority of clonal plasma cells are quiescent. In the context of a model of irreversible cell cycle exit for normal plasma cells, the initiating oncogenic event in MGUS must therefore be sufficient to establish an abnormal quiescent, but not post-mitotic state, which is not observed in normal plasma cells. A unifying model in plasma cell neoplasia has proposed that a point of convergence for initiating events is aberrant expression of Dtype cyclins, and hence the deregulation of the cell cycle (132). The mechanism of deregulation and the cyclin affected differs according to the nature of the underlying molecular abnormality, but the common event is aberrant D-type cyclin expression. Effects on p18INK4C and other negative regulators of D-type cyclins and G1/S phase progression are implicated in mediating the downstream effects of such deregulation in neoplastic plasma cells, but the cells in the early phases of disease are minimally proliferative (78). How D-type cyclin deregulation suffices to establish an aberrant state of quiescent but not irreversible cell cycle exit, while the capacity to fully differentiate is maintained, remains unclear. Direct transcriptional effects of CCND1 on cell cycle gene expression have been recently reported in other lineages and may contribute $(133,134)$, but have yet to been investigated in plasma cells.

In contrast if transit into the long-lived bone marrow plasma cell population is linked to entry into a relative quiescent state, accompanied by an intrinsic capacity for replicative self-renewal, then the initiating oncogenic event in plasma cell malignancies driving D-type cyclin expression would not be required to deregulate an entire process of irreversible cell cycle exit. Instead it would act on a differentiated and quiescent, but not post-mitotic population to reduce the threshold for cell cycle re-entry. Over time such populations would be expected to expand relative to other long-lived plasma cells leading to gradual dominance of the clone, but given a low overall rate of cell cycle re-entry would exhibit slow clonal progression. Thus a relative quiescence model would fit with the prevailing concept of plasma cell neoplasia, and would provide a simple explanation for why small neoplastic plasma cell 
populations arise quite frequently and only progress to myeloma at a low rate.

\section{SUMMARY AND PERSPECTIVES}

\section{A REPLICATIVE SELF-RENEWAL MODEL OF LONG-LIVED PC MAINTENANCE}

In a replicative self-renewal model long-lived plasma cells reside in the bone marrow niche in a quiescent state, expressing a range of cell cycle regulators, but can be triggered by cellular and immunological cues into undergoing transient episodes of replicative self-renewal at a low frequency (prevalence $<1 \%$ of plasma cells) (Figure 2A). A combination of sibling-rivalry and external competition for limited niche factors would then act to constrain population expansion and link further long-term survival to the re-establishment of quiescence. For any individual antigen-specificity the frequency of plasma cell replicative selfrenewal would be low, and occurring randomly would not be predicted to result in global impact on antibody titers at any single time-point. In the context of a plasma cell precursor with an expressed oncogene the threshold for cell cycle re-entry would effectively be reduced. However the plasma cell would remain constrained both by a requirement for physiological cues to trigger cell cycle re-entry, and by a dependence on niche signals for survival (Figure 2B). This would be expected to result in only gradual clonal expansion, which over time would manifest as a paraprotein and preferential clonal representation. Additional contributory mechanism, that have not been addressed here, could be envisaged from expressed oncogenes conferring apoptotic resistance leading to preferential survival of both daughter cells despite a normal self-renewal threshold. In either case the impact of the expressed

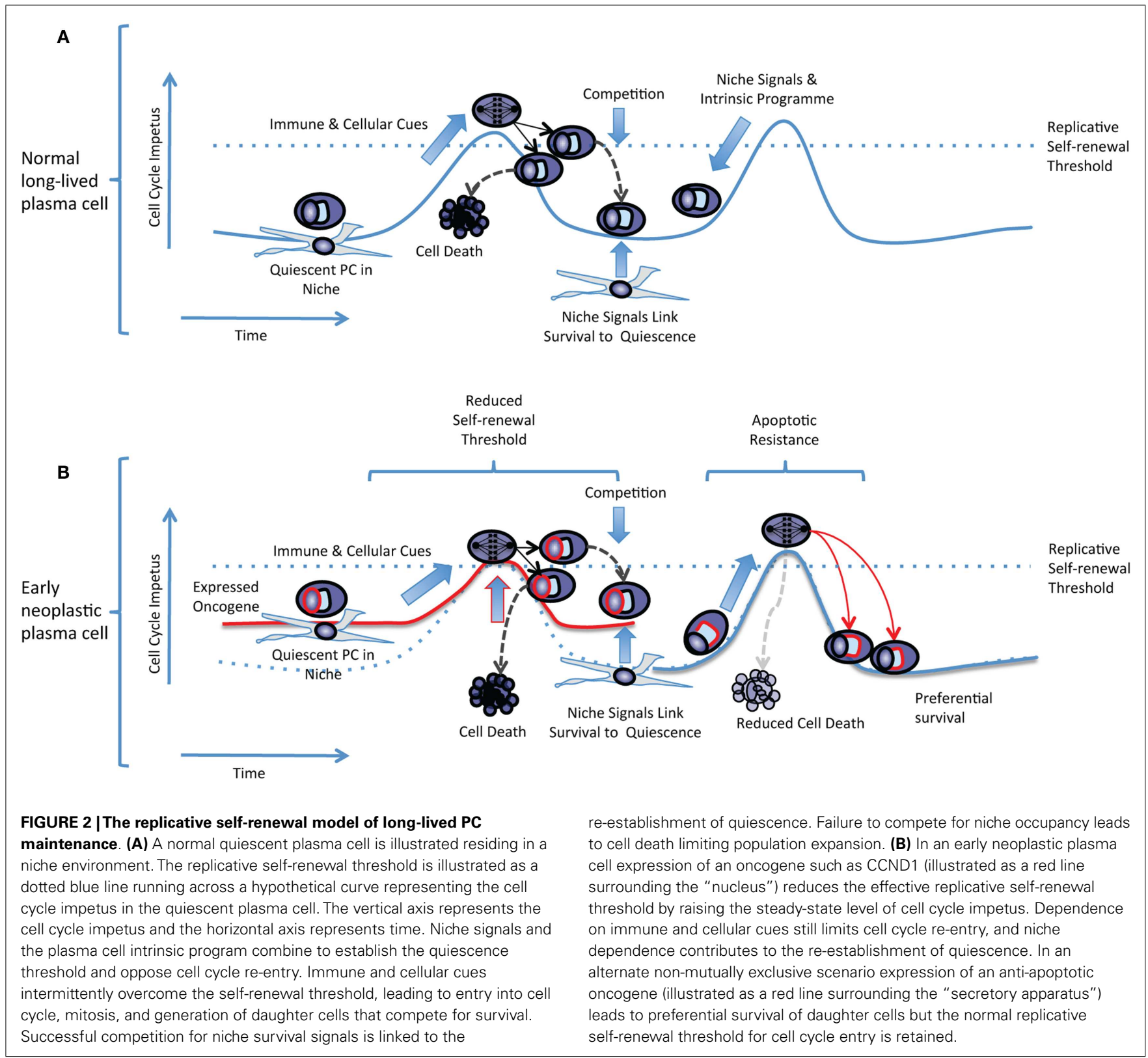


oncogene would reflect a partial deregulation of a normal feature of human plasma cell biology rather than a gross perturbation of the normal differentiation process. Over time such populations would be expected to expand relative to other long-lived plasma cells. However, given a retained dependence on niche signals and capacity for establishing the normal quiescent state, would only gradually manifest as dominant clones and exhibit slow clonal progression, thus helping to explain the population of patients with MGUS who are at low overall risk of disease progression. The transition to progressive disease would be expected to arise from acquisition of additional oncogenic events eliminating the dependence on physiologic cues for replicative self-renewal, delaying re-entry into quiescence, and establishing niche independence.

\section{PREDICTIONS OF THE MODEL}

Predictions of the replicative self-renewal model would include that: (i) a population of phenotypically mature plasma cells with markers of cell cycle should be evident at low frequency in normal bone marrow, these should include cells secreting antibodies specific for prior/historic vaccine immune responses, (ii) conditions should be identifiable that promote an exit from quiescent state and re-entry of plasma cells into short bursts of re-proliferation, (iii) niche factors promoting plasma cell survival should support quiescence, and alterations in these factors should impact on cell cycle regulatory machinery as well as survival, (iv) loss of quiescence should be accompanied by cell death if quiescence is not re-established, and (v) expression of myeloma associated oncogenes should allow plasma cell differentiation and cell cycle exit but lower the threshold for cell cycle re-entry allowing enhanced clonal re-proliferation.

\section{PERSPECTIVE}

The model of relative quiescence and replicative self-renewal in long-lived plasma cells is presented here as an alternative to the currently prevailing paradigm of irreversible cell cycle exit. The latter has deep roots in plasma cell biology, and it can be argued that no direct evidence against the prevailing paradigm currently exists, but equally in the context of long-lived plasma cells how strong is the evidence in its favor? Self-renewal is an established concept amongst other memory lymphocyte populations $(135,136)$ and has recently been extended to tissue resident macrophages (2022). While terminal differentiation is generally seen as a process opposing such a self-renewal capacity, quiescence with the capacity for replicative self-renewal has parallels in other cellular systems with equivalently high functional specialization (15-19). Testing these opposing models will provide a deeper understanding of the nature of cell cycle exit in plasma cells, the intersection of this process with the core plasma cell differentiation program, and the mechanism of early plasma cell neoplasia.

\section{ACKNOWLEDGMENTS}

I thank Dr. Gina Doody for discussion, advice, and critical review of the manuscript and Dr. Martin Turner, Dr. Andy Rawstron, and Dr. Gururaj Arumugakani for additional discussion and advice. This work was supported by a CRUK Senior Clinical Fellowship (C7845/A10066).

\section{REFERENCES}

1. Chen-Kiang S. Cell-cycle control of plasma cell differentiation and tumorigenesis. Immunol Rev (2003) 194:39-47. doi:10.1034/j.1600-065X.2003.00065.x

2. Amanna IJ, Slifka MK. Mechanisms that determine plasma cell lifespan and the duration of humoral immunity. Immunol Rev (2010) 236:125-38. doi:10.1111/j.1600-065X.2010.00912.x

3. Oracki SA, Walker JA, Hibbs ML, Corcoran LM, Tarlinton DM. Plasma cell development and survival. Immunol Rev (2010) 237:140-59. doi:10.1111/j. 1600-065X.2010.00940.x

4. Yoshida T, Mei H, Dorner T, Hiepe F, Radbruch A, Fillatreau S, et al. Memory $\mathrm{B}$ and memory plasma cells. Immunol Rev (2010) 237:117-39. doi:10.1111/j. 1600-065X.2010.00938.x

5. Slocombe T, Brown S, Miles K, Gray M, Barr TA, Gray D. Plasma cell homeostasis: the effects of chronic antigen stimulation and inflammation. JImmunol (2013) 191:3128-38. doi:10.4049/jimmunol.1301163

6. Miller JJ III. An autoradiographic study of plasma cell and lymphocyte survival in rat popliteal lymph nodes. J Immunol (1964) 92:673-81.

7. Slifka MK, Antia R, Whitmire JK, Ahmed R. Humoral immunity due to longlived plasma cells. Immunity (1998) 8:363-72. doi:10.1016/S1074-7613(00) 80541-5

8. Manz RA, Thiel A, Radbruch A. Lifetime of plasma cells in the bone marrow. Nature (1997) 388:133-4. doi:10.1038/40540

9. Gatto D, Martin SW, Bessa J, Pellicioli E, Saudan P, Hinton HJ, et al. Regulation of memory antibody levels: the role of persisting antigen versus plasma cell life span. J Immunol (2007) 178:67-76.

10. Rozanski CH, Arens R, Carlson LM, Nair J, Boise LH, Chanan-Khan AA, et al. Sustained antibody responses depend on CD28 function in bone marrowresident plasma cells. J Exp Med (2011) 208(7):1435-46. doi:10.1084/jem. 20110040

11. Ho F, Lortan JE, Maclennan IC, Khan M. Distinct short-lived and long-lived antibody-producing cell populations. Eur J Immunol (1986) 16:1297-301. doi:10.1002/eji.1830161018

12. Slifka MK, Ahmed R. B cell responses and immune memory. Dev Biol Stand (1998) 95:105-15.

13. Amanna IJ, Carlson NE, Slifka MK. Duration of humoral immunity to common viral and vaccine antigens. N Engl J Med (2007) 357:1903-15. doi:10.1056/NEJMoa066092

14. Cocco M, Stephenson S, Care MA, Newton D, Barnes NA, Davison A, et al. In vitro generation of long-lived human plasma cells. J Immunol (2012) 189(12):5773-85. doi:10.4049/jimmunol.1103720

15. Engel FB, Schebesta M, Duong MT, Lu G, Ren S, Madwed JB, et al. p38 MAP kinase inhibition enables proliferation of adult mammalian cardiomyocytes. Genes Dev (2005) 19:1175-87.

16. Bergmann O, Bhardwaj RD, Bernard S, Zdunek S, Barnabe-Heider F, Walsh $\mathrm{S}$, et al. Evidence for cardiomyocyte renewal in humans. Science (2009) 324:98-102. doi:10.1126/science. 1164680

17. Malato Y, Naqvi S, Schurmann N, Ng R, Wang B, Zape J, et al. Fate tracing of mature hepatocytes in mouse liver homeostasis and regeneration. J Clin Invest (2011) 121:4850-60. doi:10.1172/JCI59261

18. Napoli I, Noon LA, Ribeiro S, Kerai AP, Parrinello S, Rosenberg LH, et al. A central role for the ERK-signaling pathway in controlling Schwann cell plasticity and peripheral nerve regeneration in vivo. Neuron (2012) 73:729-42. doi:10.1016/j.neuron.2011.11.031

19. Senyo SE, Steinhauser ML, Pizzimenti CL, Yang VK, Cai L, Wang M, et al. Mammalian heart renewal by pre-existing cardiomyocytes. Nature (2013) 493:433-6. doi:10.1038/nature11682

20. Ajami B, Bennett JL, Krieger C, Tetzlaff W, Rossi FM. Local self-renewal can sustain CNS microglia maintenance and function throughout adult life. Nat Neurosci (2007) 10:1538-43. doi:10.1038/nn2014

21. Hashimoto D, Chow A, Noizat C, Teo P, Beasley MB, Leboeuf M, et al. Tissueresident macrophages self-maintain locally throughout adult life with minimal contribution from circulating monocytes. Immunity (2013) 38:792-804. doi:10.1016/j.immuni.2013.04.004

22. Sieweke $\mathrm{MH}$, Allen JE. Beyond stem cells: self-renewal of differentiated macrophages. Science (2013) 342(6161):1242974. doi:10.1126/science.1242974

23. Jelinek DF, Lipsky PE. The role of B cell proliferation in the generation of immunoglobulin-secreting cells in man. J Immunol (1983) 130:2597-604. 
24. Brieva JA, Roldan E, de la Sen ML, Rodriguez C. Human in vivo-induced spontaneous IgG-secreting cells from tonsil, blood and bone marrow exhibit different phenotype and functional level of maturation. Immunology (1991) 72:580-3.

25. Roldan E, Brieva JA. Terminal differentiation of human bone marrow cells capable of spontaneous and high-rate immunoglobulin secretion: role of bone marrow stromal cells and interleukin 6. Eur J Immunol (1991) 21:2671-7. doi:10.1002/eji.1830211105

26. Mei HE, Yoshida T, Sime W, Hiepe F, Thiele K, Manz RA, et al. Bloodborne human plasma cells in steady state are derived from mucosal immune responses. Blood (2009) 113:2461-9. doi:10.1182/blood-2008-04-153544

27. Robillard N, Pellat-Deceunynck C, Bataille R. Phenotypic characterization of the human myeloma cell growth fraction. Blood (2005) 105:4845-8. doi:10.1182/blood-2004-12-4700

28. Mayle A, Luo M, Jeong M, Goodell MA. Flow cytometry analysis of murine hematopoietic stem cells. Cytometry A (2013) 83:27-37. doi:10.1002/cyto.a. 22093

29. Morse L, Chen D, Franklin D, Xiong Y, Chen-Kiang S. Induction of cell cycle arrest and B cell terminal differentiation by CDK inhibitor p18(INK4c) and IL-6. Immunity (1997) 6:47-56. doi:10.1016/S1074-7613(00)80241-1

30. Tourigny MR, Ursini-Siegel J, Lee H, Toellner KM, Cunningham AF, Franklin DS, et al. CDK inhibitor p18(INK4c) is required for the generation of functional plasma cells. Immunity (2002) 17:179-89. doi:10.1016/S1074-7613(02) 00364-3

31. Jourdan M, Caraux A, De Vos J, Fiol G, Larroque M, Cognot C, et al. An in vitro model of differentiation of memory B cells into plasmablasts and plasma cells including detailed phenotypic and molecular characterization. Blood (2009) 114:5173-81. doi:10.1182/blood-2009-07-235960

32. Moser K, Tokoyoda K, Radbruch A, Maclennan I, Manz RA. Stromal niches, plasma cell differentiation and survival. Curr Opin Immunol (2006) 18:265-70. doi:10.1016/j.coi.2006.03.004

33. Radbruch A, Muehlinghaus G, Luger EO, Inamine A, Smith KG, Dorner T, et al. Competence and competition: the challenge of becoming a long-lived plasma cell. Nat Rev Immunol (2006) 6:741-50. doi:10.1038/nri1886

34. Tokoyoda K, Egawa T, Sugiyama T, Choi BI, Nagasawa T. Cellular niches controlling $\mathrm{B}$ lymphocyte behavior within bone marrow during development. Immunity (2004) 20:707-18. doi:10.1016/j.immuni.2004.05.001

35. Geffroy-Luseau A, Jego G, Bataille R, Campion L, Pellat-Deceunynck C. Osteoclasts support the survival of human plasma cells in vitro. Int Immunol (2008) 20:775-82. doi:10.1093/intimm/dxn035

36. Winter O, Moser K, Mohr E, Zotos D, Kaminski H, Szyska M, et al. Megakaryocytes constitute a functional component of a plasma cell niche in the bone marrow. Blood (2010) 116:1867-75. doi:10.1182/blood-2009-12-259457

37. Chu VT, Frohlich A, Steinhauser G, Scheel T, Roch T, Fillatreau S, et al Eosinophils are required for the maintenance of plasma cells in the bone marrow. Nat Immunol (2011) 12:151-9. doi:10.1038/ni.1981

38. Belnoue E, Tougne C, Rochat AF, Lambert PH, Pinschewer DD, Siegrist CA. Homing and adhesion patterns determine the cellular composition of the bone marrow plasma cell niche. J Immunol (2012) 188:1283-91. doi:10.4049/ jimmunol.1103169

39. Winter O, Dame C, Jundt F, Hiepe F. Pathogenic long-lived plasma cells and their survival niches in autoimmunity, malignancy, and allergy. J Immunol (2012) 189:5105-11. doi:10.4049/jimmunol.1202317

40. Arai F, Hirao A, Ohmura M, Sato H, Matsuoka S, Takubo K, et al. Tie2/angiopoietin-1 signaling regulates hematopoietic stem cell quiescence in the bone marrow niche. Cell (2004) 118:149-61. doi:10.1016/j.cell.2004.07.004

41. Qian H, Buza-Vidas N, Hyland CD, Jensen CT, Antonchuk J, Mansson R, et al. Critical role of thrombopoietin in maintaining adult quiescent hematopoietic stem cells. Cell Stem Cell (2007) 1:671-84. doi:10.1016/j.stem.2007.10.008

42. Yoshihara H, Arai F, Hosokawa K, Hagiwara T, Takubo K, Nakamura Y, et al Thrombopoietin/MPL signaling regulates hematopoietic stem cell quiescence and interaction with the osteoblastic niche. Cell Stem Cell (2007) 1:685-97. doi:10.1016/j.stem.2007.10.020

43. Fleming HE, Janzen V, Lo Celso C, Guo J, Leahy KM, Kronenberg HM, et al. Wnt signaling in the niche enforces hematopoietic stem cell quiescence and is necessary to preserve self-renewal in vivo. Cell Stem Cell (2008) 2:274-83. doi:10.1016/j.stem.2008.01.003
44. Yamazaki S, Ema H, Karlsson G, Yamaguchi T, Miyoshi H, Shioda S, et al. Nonmyelinating Schwann cells maintain hematopoietic stem cell hibernation in the bone marrow niche. Cell (2011) 147:1146-58. doi:10.1016/j.cell.2011.09.053

45. Vernino L, McAnally LM, Ramberg J, Lipsky PE. Generation of nondividing high rate Ig-secreting plasma cells in cultures of human B cells stimulated with anti-CD3-activated T cells. J Immunol (1992) 148:404-10.

46. Hodgkin PD, Lee JH, Lyons AB. B cell differentiation and isotype switching is related to division cycle number. J Exp Med (1996) 184:277-81. doi:10.1084/jem.184.1.277

47. Tangye SG, Hodgkin PD. Divide and conquer: the importance of cell division in regulating B-cell responses. Immunology (2004) 112:509-20. doi:10.1111/j. 1365-2567.2004.01950.x

48. Duffy KR, Wellard CJ, Markham JF, Zhou JH, Holmberg R, Hawkins ED, et al. Activation-induced B cell fates are selected by intracellular stochastic competition. Science (2012) 335:338-41. doi:10.1126/science.1213230

49. Miller JP, Yeh N, Vidal A, Koff A. Interweaving the cell cycle machinery with cell differentiation. Cell Cycle (2007) 6:2932-8. doi:10.4161/cc.6.23.5042

50. Bretz J, Garcia J, Huang X, Kang L, Zhang Y, Toellner KM, et al. Noxa mediates p18INK4c cell-cycle control of homeostasis in B cells and plasma cell precursors. Blood (2011) 117:2179-88. doi:10.1182/blood-2010-06-288027

51. Lin Y, Wong K, Calame K. Repression of c-myc transcription by Blimp1, an inducer of terminal B cell differentiation. Science (1997) 276:596-9. doi:10.1126/science.276.5312.596

52. Lin KI, Lin Y, Calame K. Repression of c-myc is necessary but not sufficient for terminal differentiation of B lymphocytes in vitro. Mol Cell Biol (2000) 20:8684-95. doi:10.1128/MCB.20.23.8684-8695.2000

53. Kallies A, Hasbold J, Tarlinton DM, Dietrich W, Corcoran LM, Hodgkin PD, et al. Plasma cell ontogeny defined by quantitative changes in blimp-1 expression. J Exp Med (2004) 200:967-77. doi:10.1084/jem.20040973

54. Shaffer AL, Lin KI, Kuo TC, Yu X, Hurt EM, Rosenwald A, et al. Blimp-1 orchestrates plasma cell differentiation by extinguishing the mature B cell gene expression program. Immunity (2002) 17:51-62. doi:10.1016/S1074-7613(02) 00335-7

55. Shapiro-Shelef M, Lin KI, McHeyzer-Williams LJ, Liao J, McHeyzer-Williams MG, Calame K. Blimp-1 is required for the formation of immunoglobulin secreting plasma cells and pre-plasma memory B cells. Immunity (2003) 19:607-20. doi:10.1016/S1074-7613(03)00267-X

56. Doody GM, Care MA, Burgoyne NJ, Bradford JR, Bota M, Bonifer C, et al. An extended set of PRDM1/BLIMP1 target genes links binding motif type to dynamic repression. Nucleic Acids Res (2010) 38:5336-50. doi:10.1093/nar/ gkq268

57. Yu J, Angelin-Duclos C, Greenwood J, Liao J, Calame K. Transcriptional repression by blimp-1 (PRDI-BF1) involves recruitment of histone deacetylase. Mol Cell Biol (2000) 20:2592-603. doi:10.1128/MCB.20.7.2592-2603.2000

58. Gyory I, Wu J, Fejer G, Seto E, Wright KL. PRDI-BF1 recruits the histone H3 methyltransferase G9a in transcriptional silencing. Nat Immunol (2004) 5:299-308. doi:10.1038/ni1046

59. Ancelin K, Lange UC, Hajkova P, Schneider R, Bannister AJ, Kouzarides T, et al. Blimp1 associates with Prmt5 and directs histone arginine methylation in mouse germ cells. Nat Cell Biol (2006) 8:623-30. doi:10.1038/ncb1413

60. Rutishauser RL, Martins GA, Kalachikov S, Chandele A, Parish IA, Meffre E, et al. Transcriptional repressor Blimp-1 promotes CD8(+) T cell terminal differentiation and represses the acquisition of central memory $\mathrm{T}$ cell properties. Immunity (2009) 31(2):296-308. doi:10.1016/j.immuni.2009.05.014

61. Crotty S, Johnston RJ, Schoenberger SP. Effectors and memories: Bcl-6 and Blimp-1 in T and B lymphocyte differentiation. Nat Immunol (2010) 11:114-20. doi:10.1038/ni.1837

62. Ohinata Y, Payer B, O'Carroll D, Ancelin K, Ono Y, Sano M, et al. Blimpl is a critical determinant of the germ cell lineage in mice. Nature (2005) 436:207-13. doi: $10.1038 /$ nature 03813

63. Vincent SD, Dunn NR, Sciammas R, Shapiro-Shalef M, Davis MM, Calame K, et al. The zinc finger transcriptional repressor Blimp1/Prdm 1 is dispensable for early axis formation but is required for specification of primordial germ cells in the mouse. Development (2005) 132:1315-25. doi:10.1242/dev.01711

64. Horsley V, O'Carroll D, Tooze R, Ohinata Y, Saitou M, Obukhanych T, et al. Blimp1 defines a progenitor population that governs cellular input to the sebaceous gland. Cell (2006) 126:597-609. doi:10.1016/j.cell.2006.06.048 
65. Robertson EJ, Charatsi I, Joyner CJ, Koonce CH, Morgan M, Islam A, et al. Blimp1 regulates development of the posterior forelimb, caudal pharyngeal arches, heart and sensory vibrissae in mice. Development (2007) 134:4335-45. doi:10.1242/dev.012047

66. Usui T, Wakatsuki Y, Matsunaga Y, Kaneko S, Koseki H, Kita T, et al. Overexpression of B cell-specific activator protein (BSAP/Pax-5) in a late B cell is sufficient to suppress differentiation to an Ig high producer cell with plasma cell phenotype. J Immunol (1997) 158:3197-204.

67. Lin KI, Angelin-Duclos C, Kuo TC, Calame K. Blimp-1-dependent repression of Pax-5 is required for differentiation of B cells to immunoglobulin M-secreting plasma cells. Mol Cell Biol (2002) 22:4771-80. doi:10.1128/MCB.22.13.47714780.2002

68. Mora-Lopez F, Reales E, Brieva JA, Campos-Caro A. Human BSAP and BLIMP1 confirm an autoregulatory feedback loop. Blood (2007) 110:3150-7. doi:10.1182/blood-2007-05-092262

69. Schmidlin H, Diehl SA, Nagasawa M, Scheeren FA, Schotte R, Uittenbogaart $\mathrm{CH}$, et al. Spi-B inhibits human plasma cell differentiation by repressing BLIMP1 and XBP-1 expression. Blood (2008) 112:1804-12. doi:10.1182/ blood-2008-01-136440

70. Shaffer AL, Yu X, He Y, Boldrick J, Chan EP, Staudt LM. BCL-6 represses genes that function in lymphocyte differentiation, inflammation, and cell cycle control. Immunity (2000) 13:199-212. doi:10.1016/S1074-7613(00) 00020-0

71. Tunyaplin C, Shaffer AL, Angelin-Duclos CD, Yu X, Staudt LM, Calame KL. Direct repression of prdm 1 by Bcl- 6 inhibits plasmacytic differentiation. J Immunol (2004) 173:1158-65.

72. Ochiai K, Katoh Y, Ikura T, Hoshikawa Y, Noda T, Karasuyama H, et al. Plasmacytic transcription factor Blimp-1 is repressed by Bach2 in B cells. J Biol Chem (2006) 281:38226-34. doi:10.1074/jbc.M607592200

73. Igarashi K, Ochiai K, Muto A. Architecture and dynamics of the transcription factor network that regulates B-to-plasma cell differentiation. JBiochem (2007) 141:783-9. doi:10.1093/jb/mvm106

74. Ochiai K, Muto A, Tanaka H, Takahashi S, Igarashi K. Regulation of the plasma cell transcription factor Blimp-1 gene by Bach2 and Bcl6. Int Immunol (2008) 20:453-60. doi:10.1093/intimm/dxn005

75. Muto A, Ochiai K, Kimura Y, Itoh-Nakadai A, Calame KL, Ikebe D, et al. Bach2 represses plasma cell gene regulatory network in B cells to promote antibody class switch. EMBO J (2010) 29:4048-61. doi:10.1038/emboj.2010.257

76. Fujita N, Jaye DL, Geigerman C, Akyildiz A, Mooney MR, Boss JM, et al. MTA3 and the Mi-2/NuRD complex regulate cell fate during B lymphocyte differentiation. Cell (2004) 119:75-86. doi:10.1016/j.cell.2004.09.014

77. Hideshima T, Mitsiades C, Ikeda H, Chauhan D, Raje N, Gorgun G, et al. A proto-oncogene BCL6 is up-regulated in the bone marrow microenvironment in multiple myeloma cells. Blood (2010) 115:3772-5. doi:10.1182/blood2010-02-270082

78. Kuehl WM, Bergsagel PL. Molecular pathogenesis of multiple myeloma and its premalignant precursor. J Clin Invest (2012) 122:3456-63. doi:10.1172/ JCI61188

79. Morgan GJ, Walker BA, Davies FE. The genetic architecture of multiple myeloma. Nat Rev Cancer (2012) 12:335-48. doi:10.1038/nrc3257

80. Walker BA, Wardell CP, Chiecchio L, Smith EM, Boyd KD, Neri A, et al. Aberrant global methylation patterns affect the molecular pathogenesis and prognosis of multiple myeloma. Blood (2011) 117:553-62. doi:10.1182/blood-2010-04279539

81. Sarkies P, Sale JE. Cellular epigenetic stability and cancer. Trends Genet (2012) 28:118-27. doi:10.1016/j.tig.2011.11.005

82. Montes-Moreno S, Montalban C, Piris MA. Large B-cell lymphomas with plasmablastic differentiation: a biological and therapeutic challenge. Leuk Lymphoma (2012) 53:185-94. doi:10.3109/10428194.2011.608447

83. Miller FR. The induced development and histogenesis of plasma cells. J Exp Med (1931) 54:333-47. doi:10.1084/jem.54.3.333

84. Narita M, Nunez S, Heard E, Lin AW, Hearn SA, Spector DL, et al. Rb-mediated heterochromatin formation and silencing of E2F target genes during cellular senescence. Cell (2003) 113:703-16. doi:10.1016/S0092-8674(03)00401-X

85. Ye X, Zerlanko B, Zhang R, Somaiah N, Lipinski M, Salomoni P, et al. Definition of pRB- and p53-dependent and -independent steps in HIRA/ASF1a-mediated formation of senescence-associated heterochromatin foci. Mol Cell Biol (2007) 27:2452-65. doi:10.1128/MCB.01592-06
86. Zhang R, Chen W, Adams PD. Molecular dissection of formation of senescenceassociated heterochromatin foci. Mol Cell Biol (2007) 27:2343-58. doi:10.1128/ MCB.02019-06

87. Chandra T, Kirschner K, Thuret JY, Pope BD, Ryba T, Newman S, et al. Independence of repressive histone marks and chromatin compaction during senescent heterochromatic layer formation. Mol Cell (2012) 47:203-14. doi:10.1016/j.molcel.2012.06.010

88. Zezula J, Casaccia-Bonnefil P, Ezhevsky SA, Osterhout DJ, Levine JM, Dowdy $\mathrm{SF}$, et al. p21cip1 is required for the differentiation of oligodendrocytes independently of cell cycle withdrawal. EMBO Rep (2001) 2:27-34. doi:10.1093/ embo-reports/kve008

89. Chandler H, Peters G. Stressing the cell cycle in senescence and aging. Curr Opin Cell Biol (2013) 25(6):765-71. doi:10.1016/j.ceb.2013.07.005

90. Chen HZ, Tsai SY, Leone G. Emerging roles of E2Fs in cancer: an exit from cell cycle control. Nat Rev Cancer (2009) 9:785-97. doi:10.1038/nrc2696

91. Aksoy O, Chicas A, Zeng T, Zhao Z, McCurrach M, Wang X, et al. The atypical E2F family member E2F7 couples the p53 and RB pathways during cellular senescence. Genes Dev (2012) 26:1546-57. doi:10.1101/gad.196238.112

92. Xu X, Bieda M, Jin VX, Rabinovich A, Oberley MJ, Green R, et al. A comprehensive ChIP-chip analysis of E2F1, E2F4, and E2F6 in normal and tumor cells reveals interchangeable roles of E2F family members. Genome Res (2007) 17:1550-61. doi:10.1101/gr.6783507

93. Ogawa H, Ishiguro K, Gaubatz S, Livingston DM, Nakatani Y. A complex with chromatin modifiers that occupies E2F- and Myc-responsive genes in G0 cells. Science (2002) 296:1132-6. doi:10.1126/science.1069861

94. Trimarchi JM, Fairchild B, Wen J, Lees JA. The E2F6 transcription factor is a component of the mammalian Bmil-containing polycomb complex. Proc Natl Acad Sci U S A (2001) 98:1519-24. doi:10.1073/pnas.98.4.1519

95. Attwooll C, Oddi S, Cartwright P, Prosperini E, Agger K, Steensgaard P, et al. A novel repressive E2F6 complex containing the polycomb group protein $\mathrm{EPC} 1$, that interacts with EZH2 in a proliferation-specific manner. J Biol Chem (2005) 280:1199-208. doi:10.1074/jbc.M412509200

96. Trojer P, Cao AR, Gao Z, Li Y, Zhang J, Xu X, et al. L3MBTL2 protein acts in concert with PcG protein-mediated monoubiquitination of $\mathrm{H} 2 \mathrm{~A}$ to establish a repressive chromatin structure. Mol Cell (2011) 42:438-50. doi:10.1016/j.molcel.2011.04.004

97. Ren S, Rollins BJ. Cyclin C/cdk3 promotes Rb-dependent G0 exit. Cell (2004) 117:239-51. doi:10.1016/S0092-8674(04)00300-9

98. Saxena UH, Powell CM, Fecko JK, Cacioppo R, Chou HS, Cooper GM, et al. Phosphorylation by cyclin $\mathrm{C} /$ cyclin-dependent kinase 2 following mitogenic stimulation of murine fibroblasts inhibits transcriptional activity of LSF during G1 progression. Mol Cell Biol (2009) 29:2335-45. doi:10.1128/MCB. 00687-08

99. Rickert P, Seghezzi W, Shanahan F, Cho H, Lees E. Cyclin C/CDK8 is a novel CTD kinase associated with RNA polymerase II. Oncogene (1996) 12: 2631-40.

100. Miyata Y, Liu Y, Jankovic V, Sashida G, Lee JM, Shieh JH, et al. Cyclin C regulates human hematopoietic stem/progenitor cell quiescence. Stem Cells (2010) 28:308-17. doi:10.1002/stem.270

101. Soeiro I, Mohamedali A, Romanska HM, Lea NC, Child ES, Glassford J, et al. p27Kip1 and p130 cooperate to regulate hematopoietic cell proliferation in vivo. Mol Cell Biol (2006) 26:6170-84. doi:10.1128/MCB.02182-05

102. Miyamoto K, Araki KY, Naka K, Arai F, Takubo K, Yamazaki S, et al. Foxo3a is essential for maintenance of the hematopoietic stem cell pool. Cell Stem Cell (2007) 1:101-12. doi:10.1016/j.stem.2007.02.001

103. Thompson BJ, Jankovic V, Gao J, Buonamici S, Vest A, Lee JM, et al. Control of hematopoietic stem cell quiescence by the E3 ubiquitin ligase Fbw7. J Exp Med (2008) 205:1395-408. doi:10.1084/jem.20080277

104. Reavie L, Della Gatta G, Crusio K, Aranda-Orgilles B, Buckley SM, Thompson B, et al. Regulation of hematopoietic stem cell differentiation by a single ubiquitin ligase-substrate complex. Nat Immunol (2010) 11:207-15. doi:10.1038/ni.1839

105. Welcker M, Clurman BE. FBW7 ubiquitin ligase: a tumour suppressor at the crossroads of cell division, growth and differentiation. Nat Rev Cancer (2008) 8:83-93. doi:10.1038/nrc2290

106. Huang H, Tindall DJ. Dynamic FoxO transcription factors. J Cell Sci (2007) 120:2479-87. doi:10.1242/jcs.001222

107. Kops GJ, Medema RH, Glassford J, Essers MA, Dijkers PF, Coffer PJ, et al. Control of cell cycle exit and entry by protein kinase B-regulated forkhead 
transcription factors. Mol Cell Biol (2002) 22:2025-36. doi:10.1128/MCB.22. 7.2025-2036.2002

108. Bakker WJ, Harris IS, Mak TW. FOXO3a is activated in response to hypoxic stress and inhibits HIF1-induced apoptosis via regulation of CITED2. Mol Cell (2007) 28:941-53. doi:10.1016/j.molcel.2007.10.035

109. Kranc KR, Schepers H, Rodrigues NP, Bamforth S, Villadsen E, Ferry H, et al. Cited 2 is an essential regulator of adult hematopoietic stem cells. Cell Stem Cell (2009) 5:659-65. doi:10.1016/j.stem.2009.11.001

110. Brunet A, Bonni A, Zigmond MJ, Lin MZ, Juo P, Hu LS, et al. Akt promotes cell survival by phosphorylating and inhibiting a Forkhead transcription factor. Cell (1999) 96:857-68. doi:10.1016/S0092-8674(00)80595-4

111. Brunet A, Park J, Tran H, Hu LS, Hemmings BA, Greenberg ME. Protein kinase SGK mediates survival signals by phosphorylating the forkhead transcription factor FKHRL1 (FOXO3a). Mol Cell Biol (2001) 21:952-65. doi:10.1128/MCB.21.3.952-965.2001

112. Omori SA, Cato MH, Anzelon-Mills A, Puri KD, Shapiro-Shelef M, Calame $\mathrm{K}$, et al. Regulation of class-switch recombination and plasma cell differentiation by phosphatidylinositol 3-kinase signaling. Immunity (2006) 25:545-57. doi:10.1016/j.immuni.2006.08.015

113. Landgren O, Kyle RA, Pfeiffer RM, Katzmann JA, Caporaso NE, Hayes RB, et al. Monoclonal gammopathy of undetermined significance (MGUS) consistently precedes multiple myeloma: a prospective study. Blood (2009) 113:5412-7. doi:10.1182/blood-2008-12-194241

114. Weiss BM, Abadie J, Verma P, Howard RS, Kuehl WM. A monoclonal gammopathy precedes multiple myeloma in most patients. Blood (2009) 113:5418-22. doi:10.1182/blood-2008-12-195008

115. Agarwal A, Ghobrial IM. Monoclonal gammopathy of undetermined significance and smoldering multiple myeloma: a review of the current understanding of epidemiology, biology, risk stratification, and management of myeloma precursor disease. Clin Cancer Res (2013) 19:985-94. doi:10.1158/1078-0432. CCR-12-2922

116. Egan JB, Shi CX, Tembe W, Christoforides A, Kurdoglu A, Sinari S, et al. Whole-genome sequencing of multiple myeloma from diagnosis to plasma cell leukemia reveals genomic initiating events, evolution, and clonal tides. Blood (2012) 120:1060-6. doi:10.1182/blood-2012-01-405977

117. Keats JJ, Chesi M, Egan JB, Garbitt VM, Palmer SE, Braggio E, et al. Clonal competition with alternating dominance in multiple myeloma. Blood (2012) 120:1067-76. doi:10.1182/blood-2012-01-405985

118. Walker BA, Wardell CP, Melchor L, Brioli A, Johnson DC, Kaiser MF, et al. Intraclonal heterogeneity is a critical early event in the development of myeloma and precedes the development of clinical symptoms. Leukemia (2013). doi:10.1038/leu.2013.199

119. Billadeau D, Ahmann G, Greipp P, Van Ness B. The bone marrow of multiple myeloma patients contains B cell populations at different stages of differentiation that are clonally related to the malignant plasma cell. J Exp Med (1993) 178:1023-31. doi:10.1084/jem.178.3.1023

120. Pilarski LM, Seeberger K, Coupland RW, Eshpeter A, Keats JJ, Taylor BJ, et al. Leukemic B cells clonally identical to myeloma plasma cells are myelomagenic in NOD/SCID mice. Exp Hematol (2002) 30:221-8. doi:10.1016/S0301472X(01)00788-3

121. Matsui W, Huff CA, Wang Q, Malehorn MT, Barber J, Tanhehco Y, et al. Characterization of clonogenic multiple myeloma cells. Blood (2004) 103:2332-6. doi:10.1182/blood-2003-09-3064

122. Huff CA, Matsui W. Multiple myeloma cancer stem cells. J Clin Oncol (2008) 26:2895-900. doi:10.1200/JCO.2007.15.8428

123. Leung-Hagesteijn C, Erdmann N, Cheung G, Keats JJ, Stewart AK, Reece DE, et al. Xbpls-negative tumor B cells and pre-plasmablasts mediate therapeutic proteasome inhibitor resistance in multiple myeloma. Cancer Cell (2013) 24:289-304. doi:10.1016/j.ccr.2013.08.009
124. Rasmussen T. The presence of circulating clonal CD19+ cells in multiple myeloma. Leuk Lymphoma (2001) 42:1359-66.

125. Rasmussen T, Lodahl M, Hancke S, Johnsen HE. In multiple myeloma clonotypic CD38-/CD19+/CD27+ memory B cells recirculate through bone marrow, peripheral blood and lymph nodes. Leuk Lymphoma (2004) 45:1413-7.

126. Thiago LS, Perez-Andres M, Balanzategui A, Sarasquete ME, Paiva B, JaraAcevedo M, et al. Circulating clonotypic B-cells in multiple myeloma and monoclonal gammopathy of undetermined significance. Haematologica (2013). doi:10.3324/haematol.2013.092817

127. Rasmussen T, Haaber J, Dahl IM, Knudsen LM, Kerndrup GB, Lodahl M, et al. Identification of translocation products but not K-RAS mutations in memory B cells from patients with multiple myeloma. Haematologica (2010) 95:1730-7. doi:10.3324/haematol.2010.024778

128. Yata K, Yaccoby S. The SCID-rab model: a novel in vivo system for primary human myeloma demonstrating growth of CD138-expressing malignant cells. Leukemia (2004) 18:1891-7. doi:10.1038/sj.leu.2403513

129. Hosen N, Matsuoka Y, Kishida S, Nakata J, Mizutani Y, Hasegawa K, et al. CD138-negative clonogenic cells are plasma cells but not B cells in some multiple myeloma patients. Leukemia (2012) 26:2135-41. doi:10.1038/leu.2012.80

130. Chaidos A, Barnes CP, Cowan G, May PC, Melo V, Hatjiharissi E, et al. Clinical drug resistance linked to interconvertible phenotypic and functional states of tumor-propagating cells in multiple myeloma. Blood (2013) 121:318-28. doi:10.1182/blood-2012-06-436220

131. Hosen N. Multiple myeloma-initiating cells. Int J Hematol (2013) 97:306-12. doi:10.1007/s12185-013-1293-0

132. Bergsagel PL, Kuehl WM, Zhan F, Sawyer J, Barlogie B, Shaughnessy J Jr. Cyclin D dysregulation: an early and unifying pathogenic event in multiple myeloma. Blood (2005) 106:296-303. doi:10.1182/blood-2005-01-0034

133. Bienvenu F, Jirawatnotai S, Elias JE, Meyer CA, Mizeracka K, Marson A, et al. Transcriptional role of cyclin D1 in development revealed by a geneticproteomic screen. Nature (2010) 463:374-8. doi:10.1038/nature08684

134. Casimiro MC, Crosariol M, Loro E, Ertel A, Yu Z, Dampier W, et al. ChIP sequencing of cyclin D1 reveals a transcriptional role in chromosomal instability in mice. J Clin Invest (2012) 122:833-43. doi:10.1172/JCI60256

135. Fearon DT, Manders P, Wagner SD. Arrested differentiation, the self-renewing memory lymphocyte, and vaccination. Science (2001) 293:248-50. doi:10. 1126/science. 1062589

136. Gattinoni L, Lugli E, Ji Y, Pos Z, Paulos CM, Quigley MF, et al. A human memory T cell subset with stem cell-like properties. Nat Med (2011) 17:1290-7. doi:10.1038/nm.2446

Conflict of Interest Statement: The author declares that the research was conducted in the absence of any commercial or financial relationships that could be construed as a potential conflict of interest.

Received: 01 October 2013; paper pending published: 26 October 2013; accepted: 02 December 2013; published online: 18 December 2013.

Citation: Tooze RM (2013) A replicative self-renewal model for long-lived plasma cells: questioning irreversible cell cycle exit. Front. Immunol. 4:460. doi: 10.3389/fimmu.2013.00460

This article was submitted to B Cell Biology, a section of the journal Frontiers in Immunology.

Copyright (C) 2013 Tooze. This is an open-access article distributed under the terms of the Creative Commons Attribution License (CC BY). The use, distribution or reproduction in other forums is permitted, provided the original author(s) or licensor are credited and that the original publication in this journal is cited, in accordance with accepted academic practice. No use, distribution or reproduction is permitted which does not comply with these terms. 